\title{
El cómic, una cuestión de formatos (1): de los orígenes periodísticos al comic-book ${ }^{\mathrm{I}}$
}

\author{
RUBÉN VARILLAS FERNÁNDEZ
}

\begin{abstract}
Rubén Varillas Fernández es Doctor en Filología Hispánica por la Universidad de Salamanca (donde también obtuvo la licenciatura en Filología Inglesa). Su tesis, en la que estudió los mecanismos discursivos del cómic, será la base fundamental de su libro La arquitectura de las viñetas (Viaje a Bizancio Ediciones, 2009). Ha investigado y escrito acerca de cómics en publicaciones académicas (Anthropos, Boletín Galego de Literatura, Diálogos intertextuales...), prensa (FHM, suplemento Culturas del periódico Tribuna de Salamanca...) y es autor de numerosos artículos, prólogos y reseñas dedicados al mundo del cómic. Es administrador del blog especializado en cómics Little Nemo's Kat, coordina y participa en el microprograma radiofónico "Cómics en la Biblioteca" en la Cadena SER Soria y acaba de publicar Marina está en la Luna (Thule Ediciones), su primera obra como guionista junto al dibujante Gaspar Naranjo.
\end{abstract}

\section{RESUMEN}

En el siguiente estudio nos acercaremos al cómic desde una doble perspectiva formal e historiográfica, con la intención de analizar los diferentes formatos en los que se manifiesta el discurso comicográfico y el modo en que estos surgieron y han evolucionado a lo largo de la historia del medio. Durante nuestra argumentación (que constará de dos entregas) abordaremos diferentes cuestiones críticas objeto de debate y controversia dentro de los estudios comicográficos, como pueden ser la misma naturaleza constitutiva del cómic, la importancia de las herramientas que modelan su lenguaje o la definición de conceptos tan controvertidos como los de "chiste gráfico" y "novela gráfica".

\footnotetext{
${ }^{\text {I }}$ Este estudio, así como sucederá con su segunda parte, surge como revisión y ampliación de uno de los capítulos publicados en la tesis doctoral del autor, titulada El cómic: texto y discurso. Una propuesta de análisis narratológico.
}

CuCo, Cuadernos de cómic número 1. Septiembre de 2013

CuCoEstudio 


\begin{abstract}
In the following pages we will approach the study of comics from a double formal and historical perspective in order to analyse the different formats in which a comic can be displayed and how these formats were created and developed in the history of comics. Throughout our study (which will be divided in two chapters) we will consider different controversial points regarding comics research, such as the very constitutive nature of comics, the importance of the tools which constitute its language or the definition of concepts under debate like "gag-panel" or "graphic novel".
\end{abstract}

\title{
Introducción
}

A lo largo de las siguientes páginas intentaremos acercarnos al cómic desde una perspectiva que se nos antoja fundamental tanto para entender la naturaleza y formación de su lenguaje, como a la hora de abordar de un modo coherente su evolución histórica: nos referimos a la cuestión de los formatos del cómic. Pecaríamos de ingenuos si pensáramos que conceptos como los de tira de prensa, comic-book, álbum o novela gráfica se refieren únicamente a herramientas formales o a vehículos de contenido. El empleo instrumental del binomio "forma-contenido" se revela, una vez más, demasiado simple e insuficiente cuando intentamos aplicarlo al análisis y la explicación de los formatos comicográficos.

De hecho, buena parte de las polémicas contemporáneas por lo que respecta a la definición de la palabra "cómic" y la concreción de sus elementos constituyentes arrancan, precisamente, de la falta de acuerdo que existe respecto a ese elemento de cohesión macroestructural que es el formato: ¿debemos hablar de cómic cuando estamos ante un chiste formado por una única viñeta? ¿es la de "novela gráfica" una etiqueta que define a un movimiento artístico (o escuela) dentro de la historia del cómic o se trata simplemente de un "nuevo" formato que ha irrumpido con fuerza en el siglo XXI? En las próximas páginas intentaremos aportar nuestro punto de vista acerca de estas cuestiones y varias otras $\mathrm{y}$, al mismo tiempo, recorreremos (en un viaje solo lineal en apariencia) algunos de los momentos esenciales de la historia del cómic.

CuCo, Cuadernos de cómic número 1. Septiembre de 2013 


\section{El chiste gráfico y la viñeta única}

Cuando decimos que en sus orígenes, las historias gráficas se plantearon como un conjunto de viñetas destinadas a publicaciones periodísticas, en muchos casos con un fin satírico-humorístico, inmediatamente surge la duda de si podemos hablar de un cómic constituido por una sola viñeta. Si nos atenemos a las que para nosotros son las dos características fundamentales del medio comicográfico (su lenguaje doblemente articulado - en diversos grados- en imágenes y texto y su naturaleza secuencial), podremos afirmar que una única viñeta, incluso cuando muestre una integración total de la imagen y el texto, difícilmente formará por sí sola una narración secuencial; aunque comparta con el cómic elementos comunes de su lenguaje (la mencionada doble articulación, por ejemplo). ${ }^{1}$

En una ilustración podemos encontrar componentes narrativos, lógicamente, e incluso una intención de progreso diegético, pero si esta no se integra como unidad de narración en una secuencia superior, no estaremos ante un cómic. ${ }^{2}$ Asimismo, los objetivos de una ilustración no son los mismos que los de un cómic:

Se puede partir de la siguiente consideración, no siempre verdadera pero sí suficientemente a menudo como para hacerla regular: la imagen del comic cuenta, la imagen de la ilustración comenta. En otras palabras, la ilustración es normalmente ilustración de algo, y ese algo puede existir incluso sin la ilustración: su papel es, por tanto, proporcionar un comentario externo, que añade algo al relato (o al texto en sentido general) de partida. En el cómic, por el contrario, cada viñeta tiene una función directamente narrativa; incluso en ausencia de diálogos y de didascalias o texto narrativo, la viñeta cuenta un momento de la acción que constituye parte integrante de la historieta, y prescindir de ella supone perjudicar en buena medida la comprensión. ${ }^{3}$

\footnotetext{
${ }^{1}$ La palabra "cómic", además de enunciar un medio artístico o su manifestación física (un tebeo, por ejemplo), se refiere también a un lenguaje con unas características particulares. En muchas ocasiones, otros discursos (artísticos o no) han recurrido al lenguaje comicográfico para hace valer sus propuestas: la publicidad o el arte plástico son dos ejemplos que se nos vienen inmediatamente a la cabeza.
}

2 Otra cosa son, evidentemente, aquellas series narrativas (tiras periodísticas, por ejemplo) que ocasionalmente aparecen como una única viñeta. Al formar parte de una serie narrativa más amplia, esta única viñeta sí deberá interpretarse como integrante y constructora de dicha secuenciación.

${ }^{3}$ BARBIERI, D. Los lenguajes del cómic. Barcelona, Ediciones Paidós, 1993, pp. 21-22. 
Hace bien Barbieri en matizar el alcance de sus palabras, pues no parecen encajar muy bien con algunos ejemplos concretos de expresión gráfica evolucionados a partir de la ilustración: nos referimos a los chistes gráficos en una sola viñeta o a casos como aquellas primeras "ilustraciones" de carácter satírico aparecidas en la prensa americana de finales del siglo XIX (el ejemplo de las primeras apariciones de Hogan's Alley en The New York World, sin ir más lejos: FIG. 1). Una de dos, o en estos casos se tiene que desestimar el término "ilustración" o hay que flexibilizar su uso haciéndolo más inclusivo, pues en ellos la ilustración comenta más bien poco. Lo cierto es que la mayoría de los chistes gráficos que aparecen en las páginas de cualquier periódico utilizan para su composición algunos componentes que se consideran naturales del lenguaje de los cómics (márgenes de viñeta, globos e incluso didascalias). Cabría hablar de una variante de la ilustración, o incluso de un nuevo soporte discursivo (el chiste gráfico ${ }^{4}$ ), pero, desde este punto de vista, no podríamos decir que viñetas como la de 1895 de la FIG. 1 sean un cómic (aunque fueran el desencadenante de algunos muy importantes).

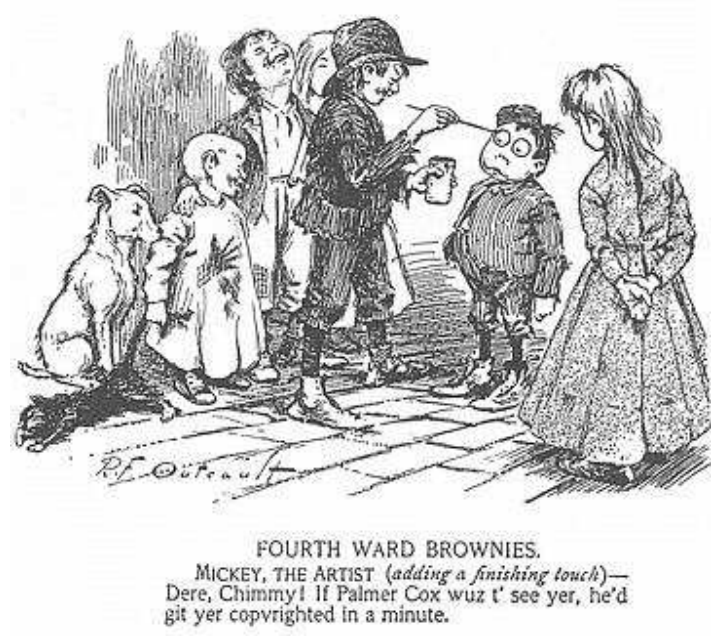

FIG. 1. Antes incluso de aparecer en ningún periódico, la revista Truth publica en un número especial, "The Art Number" (el 9 de febrero de 1895) una primera versión de la serie Hogan's Alley, en la plancha titulada "Fourth Ward Brownies". En ella, vemos dibujado en blanco y

\footnotetext{
${ }^{4}$ En inglés se le llama gag-panel, literalmente "viñeta-chiste".
} 
negro al pequeño pícaro (todavía sin el camisón amarillo, pero con casi todas sus señas de identidad), cuya viñeta única pasaría a publicarse días después (17 de febrero) en The New York World de Joseph Pulitzer y a partir de 1896 en el New York Journal de William Randolph Hearst, ya con el nombre de The Yellow Kid. ${ }^{5}$

Existen, desde luego, numerosas voces que hablan en un sentido contrario al aquí expuesto y consideran que los chistes gráficos en una sola viñeta son uno de tantos formatos posibles dentro de las narraciones gráficas. Así lo afirman estudiosos como Robert Harvey, ${ }^{6}$ Jesús Jiménez Varea, ${ }^{7}$ Santiago García ${ }^{8}$ o Daniel Gómez Salamanca, ${ }^{9}$ por ejemplo.

\section{Las tiras de prensa y las planchas dominicales: la explosión del medio}

Poco tiempo después de ese año 1895, la presencia de historias gráficas se hizo imprescindible en casi todos los dominicales de EE. UU. (bien ocupando una página

\footnotetext{
${ }^{5}$ Blackbeard, B. The Yellow Kid A Centenial Celebration of the Kid Who Started the Comics: R. F. Outcault. Northampton (Massachussets), Kitchen Sink Press, 1995, p. 26.

${ }^{6}$ Robert Harvey es uno de los autores no está de acuerdo a la hora de desmarcar al chiste gráfico (gagpanel o gag-cartoon) del concepto de cómic:

... gag cartoons fall outside most definitions of comics. But not mine. In my view, comics consist of pictorial narratives or expositions in which words (often lettered into the picture area within speech balloons) usually contribute to the meaning of the pictures and vice versa. A pictorial narrative uses a sequence of yuxtaposed pictures (i.e., "a strip" of pictures); pictorial exposition may do the same - or may not (as in single-panel cartoons-political cartoons as well as gag cartoons) (HARVEY, R. The Art of the Comic-book. An Aesthetic History. Jackson, University Press of Mississippi, 2001, p. 76).
}

${ }^{7}$ JimÉnEZ VAREA, J. Narrativa de la historieta: Análisis narratológico del cómic a través de la obra de Alan Moore. GuARINOS Galán, V. (dir.). Tesis doctoral. Universidad de Sevilla, Sevilla, 2002.

${ }^{8}$ GARCíA, S. La novela gráfica. Bilbao, Astiberri, 2010.

${ }^{9}$ Gómez SalamancA, D. Tebeo, cómic y novela gráfica: La influencia de la novela gráfica en la industria del cómic en España. ROM RodRíGueZ, J. (dir.). Tesis doctoral. Universitat Ramon Llull, Barcelona, 2013.

CuCo, Cuadernos de cómic número 1. Septiembre de 2013 
entera o un fragmento de esta ${ }^{10}$ ), al mismo tiempo que alternaba con las viñetas en blanco y negro que aparecían diariamente en el interior de los periódicos. Es en 1907 cuando Bud Fisher publica su primera tira cómica (comic strip), dando origen a uno de los formatos más populares y extendidos de la narración gráfica — no hace falta señalar cuántos millones de personas posan diariamente sus ojos, aunque sea solo durante unos segundos, en las tiras gráficas que casi todos los periódicos del mundo publican.

La daily, o "tira diaria", es un comic ${ }^{11}$ de formato rectangular, integrado por una hilera de varias viñetas, aplicado a insertarse los días laborables en las páginas a blanco y negro del periódico. Antes de lograr su pleno arraigo, las dailies se dispersaban por el interior del diario; al cabo de un tiempo, confluyeron en una sección cotidiana fija, formando la habitual página o doble página de comics. El invento, a pesar de alguna frustrada iniciativa precedente, se atribuye a Bud Fisher (1885-1954) en San Francisco a través de la serie denominada en principio A. Mutt. El arranque de la misma tuvo lugar el 15 de noviembre de 1907; (...) la tira pasó a llamarse tiempo después Mutt and Jeff, constituyendo esta pareja masculina el germen de otras muchas en el ámbito de la comicidad norteamericana. $^{12}$

Desde el primer momento, la tira de prensa se convierte en uno de los formatos habituales de narración gráfica. Un análisis detallado de las cientos de series (desarrolladas tanto en las páginas dominicales como en las tiras diarias) que pueblan la prensa americana desde la primera década del siglo Xx, nos ayudaría a entender la evolución del medio. Destaca en esta proliferación el papel de los syndicates, empresas

\footnotetext{
${ }^{10}$ Respecto al formato de los cómics en la prensa de estos años, señala Javier Coma:
}

En aquellos años, los comics (que aún no eran llamados así, sino funnies, de funny, "divertido") se publicaban preferentemente, (...) en los suplementos dominicales y a color; el formato habitual de impresión era el de una página, recurriéndose también a la mitad horizontal de esta superficie. De ahí nace el nombre de sunday para referirse a la entrega de un comic publicada a página entera o en un amplio fragmento de la misma el domingo en color; pero en una definición englobadora de todos los usos de este concepto, cabría tener en cuenta que necesidades de espacio y suplementos sabatinos han obligado a menudo a imprimir una sunday en sábado y en blanco y negro... (COMA, J. Del gato Félix al gato Fritz. Historia de los comics. Barcelona, Editorial Gustavo Pili, 1979, p. 12).

${ }^{11}$ De nuevo se utiliza la palabra comic, integrada al discurso en castellano ( pero sin la tilde preceptiva que exigirían las reglas de acentuación españolas.

${ }^{12}$ ComA, J. Op. cit. p. 16. 
encargadas de la gestión, promoción y distribución de los cómics a los diferentes periódicos y medios de publicación:

La influencia de los syndicates en los comics se manifiesta rápidamente por razones obvias: era necesario unificar los formatos de dailies y sundays a fin de poder adaptarse a las diversas dimensiones de los periódicos clientes o potenciales compradores. Pero esta uniformidad se extendía también al contenido ideológico, a fin de evitar cualquier posible negativa de adquisición en función de aquel (...). De ahí que los syndicates impusieran una rigurosa censura a sus autores de comics, sobre todo en lo referente a erotismo, violencia, problemática racial y religiosa, y crítica del sistema social y político norteamericano. ${ }^{13}$

La circulación organizada de los materiales gráficos tendrá un doble efecto: permitirá, por un lado, la profesionalización de los autores, y por otro, favorecerá la extensión geográfica de los cómics, contribuyendo a potenciar ese carácter popular que le caracteriza en sus comienzos. Una misma tira podía aparecer en distintas publicaciones del país, hecho que ayudaba a la divulgación de los hallazgos y a la evolución del medio.

Rápidamente, los mismos temas se repiten en series diferentes aprovechando el tirón de una primera iniciativa exitosa: las series familiares (family-strips), las series con chica (girl-strips), o las series con niño/s, se convierten en auténticos géneros, con unos elementos comunes claros y ligeros factores de variación que no alteran esa homogeneidad genérica. Los pequeños hallazgos que hacen evolucionar el medio son constantes en estas primeras épocas: las tiras pasan de ser autoconclusivas a serializar un mismo conflicto a lo largo de varios días, meses o incluso años:

Mirando las tiras de humor de los años 30 (..), se hace evidente un hecho importante cuando se contempla la evolución de la historia del comic.

Ese hecho es la aparición del factor de continuidad. Al igual que otros aspectos que hemos examinado en estas series, el nuevo elemento en su diseño, mejor aún, el nuevo modo de expresión, no se produjo casualmente. La entidad misma del comic dominical a color, la aparición de la sindicación y sus efectos, la evolución de la tira diaria, todos esos factores eran hijos de dos padres: la Creatividad y la Comercialidad.

\footnotetext{
${ }^{13}$ Ibíd., p. 31.
} 
Y eso ocurrió con el mecanismo de la continuidad. Hay pocas razones determinantes que obliguen a un creador a limitar su papel a empezar y terminar una historia nuevamente cada día, especialmente cuando solo dispone de unos pocos centímetros de papel para realizarla. ${ }^{14}$

No obstante, la idea de continuidad es bastante anterior a la década de los treinta, como señala el mismo Marschall:

Muchos lectores habían sido inducidos a creer que no existían historias en tiras antes de que Tarzán y Buck Rogers hicieran su aparición en 1929 (y por coincidencia el mismo día). Otros más informados puntualizarían que los episodios de aventuras humorísticas de Wash Tubs, que comenzaron en 1924, pueden considerarse como la línea de partida para la nueva forma artística de las emociones arrastradas día a día. La verdad es que las continuidades (continuidad de historias, tramas progresivas, reparto regular de personajes e incluso el suspense) formaban parte de los elementos del comic desde sus mismos comienzos. ${ }^{15}$

Maurice Horn en "La continuidad en los comics", añade algunos ejemplos concretos, que arrojan luz sobre este aspecto y establecen algunas consideraciones bibliográficas esclarecedoras acerca de la cronología en la aparición de la continuidad:

Desde luego las primeras tiras, como The Katzenjammer Kids, usaron la continuidad casi desde sus comienzos, en el sentido de que, ocasionalmente una página dominical podía comenzar donde había terminado la precedente. De modo más consistente, F. B. Opper, ya en 1903, introdujo el suspense de la situación de peligro de una semana a otra en Happy Hooligan y Alphonse and Gaston, dejando a los héroes colgando de un aerostato o prisioneros de árabes vendedores de esclavos al final del episodio para rescatarles al domingo siguiente. La continuidad como una característica narrativa usada de modo absoluto a través de toda una serie de comic, sin embargo, no se estableció hasta la aparición de Hairbreadth Harry. ${ }^{16}$

Sea como fuere, la búsqueda de continuidad entre las tiras diarias y las grandes planchas dominicales (sundays) había de tener unos réditos claros para sus autores en términos de creatividad y control argumental. Estando las historias, como estaban,

\footnotetext{
${ }^{14}$ MARSChALl, R. "Cuando reinaban los relatos. Los años treinta, era de las series con continuidad", en COMA, J. (coord.). Historia de los comics. Vol. 1, Barcelona, Toutain Editor, 1982-1983, p. 113.

${ }^{15}$ Ibíd., p. 114.

${ }^{16}$ HoRn, M. "La continuidad en los comics", en COMA, J. (coord.). Historia de los comics. Vol. 1, Barcelona, Toutain Editor, 1982-1983, pp. 85-86.
} 
supeditadas a un seguimiento regular en prensa por parte de sus lectores, se hacían absolutamente necesarios mecanismos narrativos que garantizaran, por un lado, el seguimiento sencillo de la trama (aún cuando se perdiera alguna entrega diaria o incluso cuando solo se siguieran los sundays) y, por otro, un índice de interés suficiente para esperar con ansiedad la entrega del día siguiente (de la que podía incluso depender el nivel de ventas del periódico). Leonard Starr, creador de la serie realista On Stage para el Chicago Tribune Syndicate, relata con un punto de ironía, sus premisas creadoras cuando se enfrentaba a esta ardua tarea, estableciendo un curioso parangón entre el cómic y la obra teatral: ${ }^{17}$

\begin{abstract}
... descubrí que una "comic strip" (serie de comics) es una obra teatral, digamos que en diez actos si tu secuencia va a aparecer durante diez semanas (...). Además, tienes siete escenas (una por cada día de la semana) por acto y hay veinticuatro horas entre el momento en que baja el telón y el momento en que vuelve a subir. Cada día tienes que hacer un resumen para que el lector recuerde dónde estaba el día antes, tienes que hacer avanzar el argumento y luego tienes que hacer una "línea telón" que induzca al lector a volver al día siguiente. Entre una plancha dominical y la siguiente narras los puntos principales del argumento, de modo que el desarrollo de la historia vaya subiendo durante la semana y alcance su culminación en la plancha dominical, que a su vez requiere un resumen para aquellos periódicos que no publican tu tira el domingo. Esto se convierte casi en un problema de álgebra en lo que se refiere a su preparación mecánica. ${ }^{18}$
\end{abstract}

En esta búsqueda de continuidad, se llega a casos como el de Frank King, que en Gasoline Alley (aparece por primera vez como publicación dominical en 1918) abre una serie en la que los personajes sufren y envejecen con el paso del tiempo a la misma velocidad que lo hacen sus lectores; se hacen adultos, se casan, tienen hijos, etc. La muerte de King en 1969 no supuso el final de la serie, sino que ya antes de esa fecha

17 Aunque la entrevista de la que procede este fragmento fue inicialmente publicada en Cartoonist Profiles, nosotros hemos recurrido al extracto traducido que Javier Coma incluyó en el primer volumen de la Historia de los comics como testimonio ilustrador del artículo de Maurice Horn, "Realismo y relevancia en los comics" (pp. 273-280).

${ }^{18}$ HORN, M. Op. cit. p. 277.

CuCo, Cuadernos de cómic número 1. Septiembre de 2013

CuCoEstudio 
esta había sido encomendada a otros autores, que la continúan hasta hoy en día (FIG. 2). ${ }^{19}$

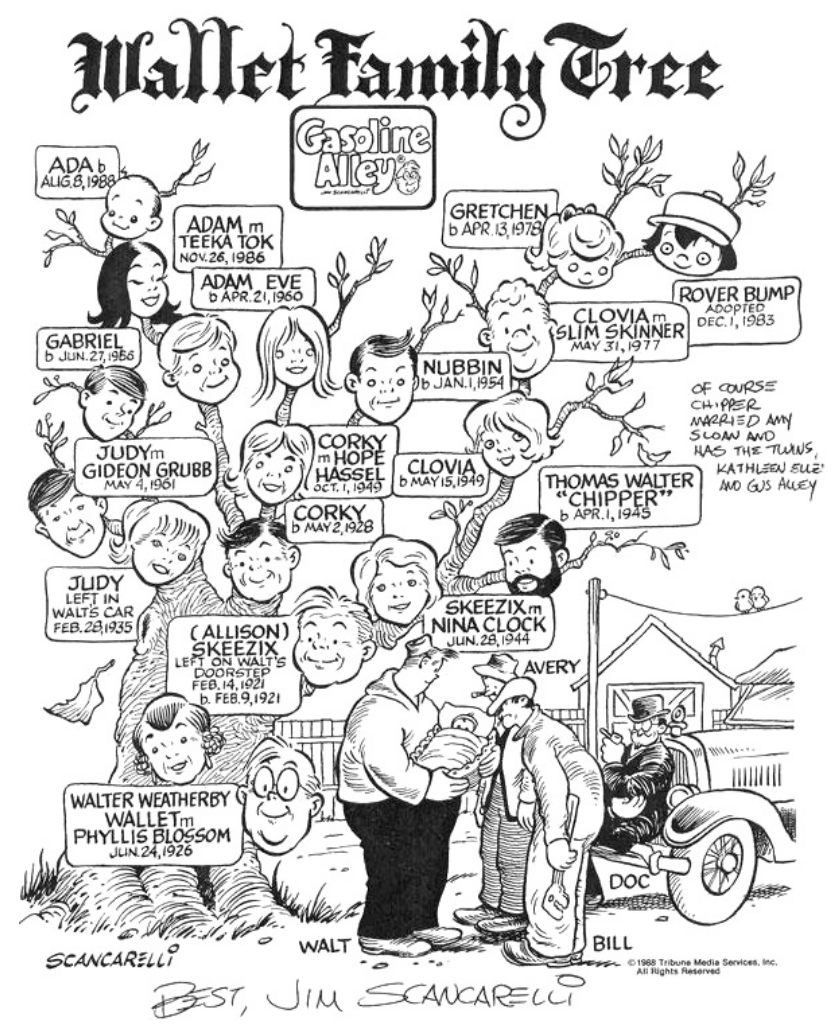

FIG. 2. Jim Scancarelli, que se hace cargo de la serie en abril de 1986, realizó un árbol familiar con la evolución de todos los personajes de la serie, con la

19 Esta es una práctica harto frecuente en la historia del cómic periodístico americano. Al ser los periódicos, primero, y los syndicates, tiempo después, quienes poseían los derechos sobre sus series, podían permitirse encargar su realización a otros autores si, por un caso, el creador original abandonaba el periódico o decidía cambiar de historia. Así sucedía cuando la serie tenía éxito entre los lectores, que a veces eran quienes con más insistencia exigían su continuación. En el caso concreto de cómics y personajes como el de The Yellow Kid, se da la circunstancia curiosa de que los tribunales que dirimieron el pleito entre el periódico iniciador de la serie (New York World) y el que había adquirido posteriormente los servicios de su autor (New York Journal), determinaron que la serie y el nombre del personaje continuarían manos de R.F. Outcault, el autor, (la serie se llamará The Yellow Kid) pero que el periódico que lo sacó a la luz tenía derecho a utilizar el personaje siempre que se le diera otro título a la tira (Hogan's Alley). Problemas similares acuciaron al célebre W. McCay y a su Little Nemo in Slumberland.

Las grandes casas de cómics de superhéroes aún hoy en día son en muchos casos plenas poseedoras de los derechos sobre sus personajes, en detrimento de los autores. En consecuencia, un mismo superhéroe puede haber sido dibujado y guionizado por cientos de artistas y artesanos al servicio de la compañía sin que el creador original cobre derechos de ningún tipo por la explotación de su obra.

CuCo, Cuadernos de cómic número 1. Septiembre de 2013 
intención de regalárselo a todos aquellos lectores que lo solicitaran; la respuesta fue abrumadora, más de 100.000 interesados lo solicitaron (uclick.com, http://content.uclick.com/content/tmgas.html, consultado el 2 de noviembre de 2004).

En un primer momento, las tiras diarias no tenían continuidad en la página dominical, aunque las dos pudieran estar dedicadas a una misma serie; Little Orphan Annie, ideada en 1924 por Harold Gray, inaugura la evolución de la historia desarrollada por las tiras diarias en las páginas del fin de semana; se crea un precedente que se repetirá con insistencia a partir de entonces. ${ }^{20}$

En España encontramos testimonios de cómics serializados desde prácticamente sus primeras publicaciones en la prensa de finales del siglo XIX:

... la publicación fundamental para documentar los primeros pasos de la primitiva historieta hecha en Madrid es La Caricatura, que comenzó a editarse en 1884, con Eduardo Sáenz Hermúa, más conocido por su seudónimo de Mecachis, como director artístico (...) Aunque las historietas solían publicarse en cualquier página de la revista, excepto en la portada, las más importantes aparecían en la doble página central y con frecuencia continuaban de una a otra semana. $^{21}$

\section{La revista europea: el éxito de los cómics periódicos infantiles}

El desarrollo editorial del cómic en Europa, y en España concretamente, durante los primeros años del siglo está condicionado por una relación de parasitismo respecto a las publicaciones periodísticas. Las historietas se inscribían dentro del marco general del periódico o/y la revista junto a otros elementos y secciones de entretenimiento (narraciones literarias, chistes, ilustraciones, jeroglíficos, crucigramas, etc.). La personalidad del nuevo modelo discursivo se veía limitada en casi todas sus facetas: los temas se movían en el territorio de la anécdota costumbrista (cuanto menos audaz,

\footnotetext{
${ }^{20}$ Para una información mucho más pormenorizada del tema, remitimos al ya citado estudio de Javier Coma, Del gato Felix al gato Fritz (Historia de los comics).

${ }^{21}$ Martín, A. Historia del cómic español: 1875-1939. Barcelona, Editorial Gustavo Gili, 1978, pp. 2021.
}

CuCo, Cuadernos de cómic número 1. Septiembre de 2013 
menos problemas causaba a la publicación que la incluía); la combinación de los dos lenguajes estaba aún muy influida por el peso de las didascalias explicativas a pie de viñeta, con lo cual en muchos casos la imagen funcionaba como simple ilustración del texto. aun así, existe una intención evidente por "contar" de una forma secuenciada, buscando la continuidad narrativa entre una viñeta y la siguiente. La instauración del bocadillo en España como elemento habitual se hace esperar varias décadas, aunque existen numerosos testimonios dispersos bastante tempranos. ${ }^{22}$ Más exitosa es la implantación del recuadro de la viñeta, que se convierte en un instrumento habitual a partir de 1910.

La autonomía del cómic en España se alcanza, de un modo relativo, a partir de la publicación de ciertas revistas destinadas a un público infantil durante la segunda década del siglo XX. La situación prominente de la nueva burguesía urbana (fenómeno de alcance europeo), así como el crecimiento de los niveles educativos y de alfabetización, genera una demanda de prensa escrita desconocida hasta entonces. Entre los destinatarios de esas publicaciones aparece un público infantil de clase media-alta con tiempo libre para leer y cierto poder adquisitivo. La nueva prensa estará orientada al entretenimiento más que a la instrucción moralizante, lo cual ya supone una novedad evidente frente a similares publicaciones precedentes.

Es sobre todo en Barcelona donde se editará “... una prensa basada en la historieta, en una zona vaga entre la revista humorística y la revista infantil...". ${ }^{23}$ Las más importantes serán: Dominguín (1915), Charlot (1916) y TBO (1917). Respecto a Dominguín y las historietas que en ella se publicaban, A. Martín comenta:

\footnotetext{
22 Independientemente del primitivo uso del seudo-bocadillo que hemos visto en El telégrafo sin hilos (1898) de Xaudaró, Antonio Martín atribuye a dibujantes como Atiza (colaborador en diversas revistas de principios de siglo como Nuevo Mundo o Gente Menuda) o José Robledano (que publicó historietas en Infancia o en Buen Humor, tiempo después) la introducción del bocadillo en el cómic español; todo ello durante la primera década del siglo (Op. cit. pp. 43-49).

${ }^{23}$ Martín, A. Op. cit. p. 58.
} 
La revista se compone de cuatro páginas de gran formato, según el modelo del Corriere dei Piccoli italiano creado en 1908, y en cada página se publica una historieta de humor completa, que en algunos casos es protagonizada por personajes fijos que dan unidad a cada entrega y valor de serie al conjunto (...) Ninguno de estos comics aporta nada nuevo a la etapa anterior, ya que el texto no se integra en la viñeta y tampoco el dibujo ofrece novedades expresivas. La importancia del ejemplo radica en la propia revista, puesto que es la primera vez que en España se presenta con semejante dignidad editorial la historieta, a base de grandes viñetas, con un dibujo eficaz, impresa en colores de gran limpieza, formando un conjunto que no tiene que justificarse por su servidumbre a los espacios literarios. $^{24}$

Con menor riqueza de medios (inicialmente constaba de ocho páginas publicadas a un solo color; a dos tintas a partir del número 10), pero con planteamientos editoriales similares, TBO adquirirá una popularidad creciente que hacen de ella la revista de cómics más longeva de nuestro país. Inicialmente editada por Arturo Suárez, pronto recae en manos de Joaquín Buigas, artífice de su verdadera explosión (dirigiendo progresivamente sus contenidos hacia el predominio casi absoluto de la narración gráfica). El nacimiento de la palabra "tebeo" no es más que un reflejo de ese enorme éxito. Uno de los grandes hallazgos de $T B O$ según A. Martín, reside en que:

... se aparta de las anteriores revistas para niños, en las que la intención formativa superaba a la recreativa, y también de la simple revista de humor, dirigida a un público indiscriminado. De hecho, se trataba de recoger una idea que estaba en el ambiente y aplicarla al público infantil: la creación de una prensa totalmente descomprometida de vínculos de partidos y de grupos de presión y desprovista de intenciones pedagógicas e ideológicas, una prensa estrictamente recreativa cuyo motor fuera exclusivamente el interés económico de la empresa editorial. ${ }^{25}$

La línea abierta por las tres publicaciones pioneras citadas, sobre todo por $T B O$, facilitó la ampliación del espectro de lectores a que iba dirigido este tipo de prensa. Pronto se empezaron a editar revistas de cómics, a un bajo coste editorial, destinadas a un público con poco poder adquisitivo. Es el caso de Historietas infantiles ${ }^{26}$ (1918),

\footnotetext{
${ }^{24}$ Ibíd., pp. 58-59.

${ }^{25}$ Ibíd., p. 60.

${ }^{26}$ Por primera vez, Heras centra la revista en torno al cómic, eliminando otros materiales ajenos al mismo, pero hasta entonces habituales en las revistas infantiles (chistes, cuentos, ilustraciones, etc.).
}

CuCo, Cuadernos de cómic número 1. Septiembre de 2013 
editada por E. Heras, o Pulgarcito (1921), de Bruguera. En todo caso, parece claro que en España, el cómic siguió siendo durante mucho tiempo una cuestión mayoritariamente infantil.

Volveremos a hablar de revistas más adelante, ampliando el alcance del término y nuestro espectro de visión.

\section{EI nacimiento de un formato revolucionario: el comic-book}

De lo aquí expuesto, se deduce que durante muchos años la publicación de historietas respondió a unos planteamientos similares: una tira formada por varias viñetas o una página que se integraban en el formato de un periódico, o, como en los casos españoles y europeos, periódicos dirigidos a un público infantil, formados por varias páginas de historietas. En todos los casos, el cómic vive supeditado a unos soportes y mecanismos editoriales ajenos (los de la prensa), demostrándose incapaz de generar unos formatos propios que se adapten a sus necesidades expresivas. El sistema de publicación supuso una constricción evidente - espacial y temática — a la hora de permitir la evolución del cómic como vehículo artístico. ${ }^{27}$ Sin embargo, a finales de los años treinta el mundo de las historias gráficas recibe una bocanada de aire fresco con la consolidación del comicbook (cuaderno de pequeño tamaño, con varias páginas, que se publicaba regularmente, y que, en castellano, se ha llamado con mucha propiedad "tebeo" ${ }^{28}$ ). Sus orígenes

${ }^{27}$ Pese a lo cual, ya en estos momentos seminales encontramos algunos ejemplos de historias gráficas sorprendentemente maduras y de una calidad técnica sin parangón. El caso más destacado es, como veremos luego, el de Little Nemo in Slumberland, creación de Winsor McCay, que se publicó regularmente en diversos periódicos americanos durante más de diez años (su primera aparición tuvo lugar el 15 de octubre de 1905 en el The New York Herald).

${ }^{28}$ Aunque en nuestro país el término "tebeo" ha tenido un sentido mucho más amplio y abarcador del aquí señalado y se ha empleado con frecuencia como sinónimo de "cómic". Para otros críticos, como Manuel Barrero (creador del archivo online Tebeosfera), el de "historieta" sería el único término verdaderamente aceptable en español a la hora de referirse al tipo de narración gráfica que nos ocupa.

CuCo, Cuadernos de cómic número 1. Septiembre de 2013

CuCoEstudio 
americanos están condicionados por diversos factores, con una mención especial de los condicionantes técnicos:

La clave de la ascendencia que con el tiempo adquiriría el "comic-book" se hallaba en las prensas a cuatro colores que se utilizaban para imprimir las planchas dominicales. Doblada una vez, la plancha dominical de tamaño normal adquiría forma de tabloide. Doblada otra vez, adquiriría el formato de "comicbook", pero durante mucho tiempo a nadie se le ocurrió dar ese segundo paso y luego encuadernar las páginas dobladas para formar una revista. ${ }^{29}$

Continúa Barrier señalando, que ya desde un primer momento en el mercado americano (como también harían los editores de cómics europeos) aparecen recopilaciones de tiras y páginas previamente publicadas en prensa:

En fecha tan temprana como marzo de 1897, solo unos meses después de que los comics asumieran su forma definitiva, se publicó en Nueva York una colección de The Yellow Kid, de R. F. Outcault, aunque más como libro que como revista.

En todo caso, no es hasta 1929 cuando la Dell Publishing Company lanza al mercado The Funnies, una revista con formato tabloide (con el mismo tamaño que un periódico, entonces) que:
... más que cualquier otra publicación aparecida hasta entonces, prefiguró el moderno "comic-book": se publicaba con regularidad; todas sus páginas eran en color (la mayoría de las reimpresiones anteriores eran en blanco y negro); se vendía en los quioscos por diez centavos; y su contenido era original en lugar de comics ya publicados en la prensa.

El hecho es que en sus primeros números The Funnies incluyó material previamente publicado, aunque más tarde comenzaría a incluir material propio. Este comic-book pionero solo aguantó en el mercado durante treinta y seis números, pero la puerta ya estaba abierta para que otros editores lanzaran productos similares con un tamaño más manejable: el que resultaba de doblar las planchas una vez más, como hemos señalado más arriba. Fueron Harry Wildenberg, George Janosik y Max C. Gaines quienes, un año antes de la aparición de Famous Funnies en 1934 (el que para muchos es el primer comic-book de la historia), habían decidido doblar el formato tabloide para

\footnotetext{
${ }^{29}$ BARRIER, M. "El nacimiento del 'comic-book'. El largo camino hacia 'Famous Funnies' y Superman”, en ComA, J. (coord.). Historia de los comics. Vol. 1, Barcelona, Toutain Editor, 1982-1983, p. 198.
} 
obtener una revista manejable (FIG. 3). La revista resultante, Funnies on Parade, incluía reedición de tiras célebres de personajes de prensa (Mutt and Jeff, Hairbreadth Harry, etc.) y se regalaba a todo aquel que enviara cupones de compra de los productos de limpieza Proctor and Gamble. El mismo editor de The Funnies, George Delacorte, recurriría a este nuevo formato cinco años más tarde, para resucitar su antiguo proyecto editorial, esta vez bajo la mencionada etiqueta de Famous Funnies, con una distribución de treinta y cinco mil ejemplares, también muestra publicitaria gratuita (dos números). La editorial Eastern Color hizo suyo el proyecto y continuó con la edición de Famous Funnies, ya en los quioscos, empezando la serie desde el número uno, con reimpresión de material antiguo. El éxito de ventas abrió la puerta definitivamente a otras muchas publicaciones con material propio, la primera, New Fun, en 1935 (primero en formato tabloide y ya como comic-book bajo el nombre de More Fun a partir del número siete).

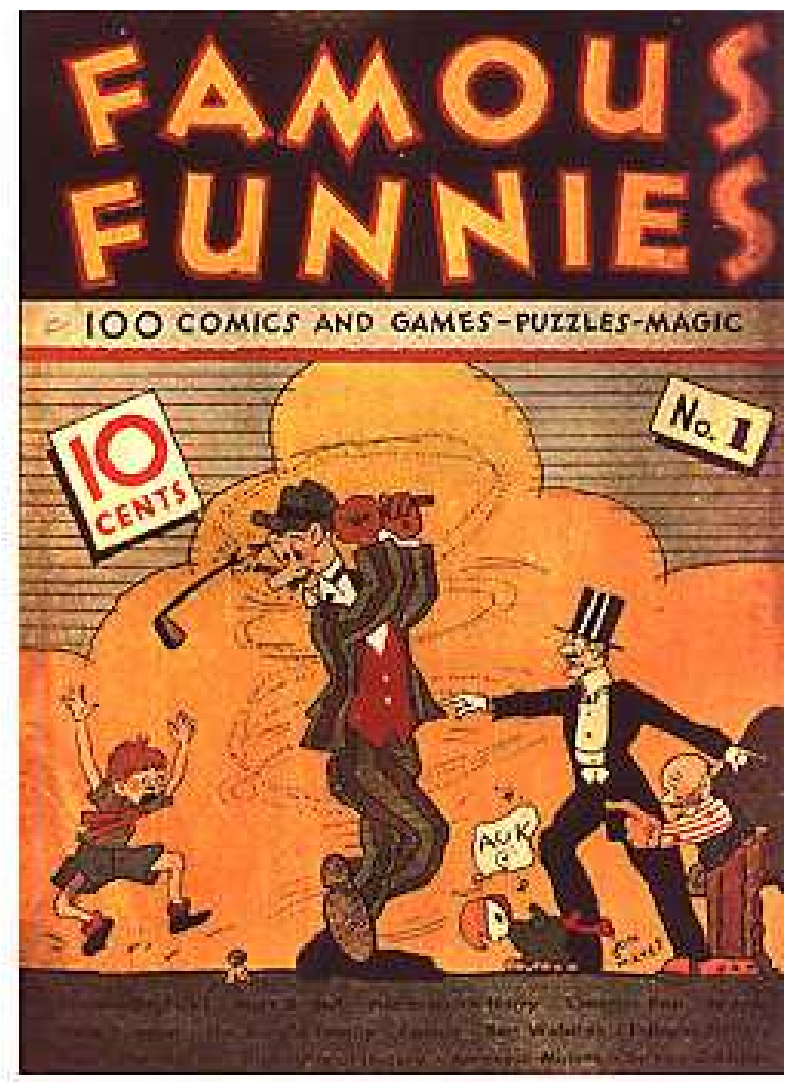

FIG. 3. Portada de Famous Funnies, con Mutt and Jeff como protagonistas principales (Julio, 1934).

CuCo, Cuadernos de cómic número 1. Septiembre de 2013 
El resultado, lo que hoy se conoce como comic-book tuvo un éxito fulgurante entre el público más joven (aunque no solamente entre ellos); las consecuencias fueron evidentes:

Los comics no se emanciparon de la dependencia de los periódicos hasta que comenzaron a difundirse los comic-books (libros de comics), como publicaciones autónomas del género. Los primeros ejemplares, aparecidos en 1929 con el título The Funnies, solo contenían reimpresiones del material previamente publicado en los periódicos. Los comic-books, utilizados durante los primeros años de la Depresión como regalo publicitario para estimular las ventas, se emanciparon de esta servidumbre comercial con Famous Funnies (1934), y desde la aparición de New Fun (1935) publicaron material original, especialmente creado para esta modalidad editora. ${ }^{30}$

Sin embargo, el éxito de los comic-books se generalizará sobre todo en los últimos años de la década con revistas como Detective Comics (1937) o Action Comics (1938), que incluían diferentes historias autoconclusivas en torno a la figura de personajes fijos: vaqueros, detectives o superhéroes como Superman, protagonista indiscutible, atendiendo a su importancia histórica, de aquel primer número de Action Comics (FIG. 4):

\begin{abstract}
"Superman creó literalmente esta industria", dijo Carmine Infantino cuando era presidente de DC Comics, los editores de Superman. "Antes de Superman los "comics books" eran en su mayor parte reimpresiones de las tiras de los periódicos, cualquier cosa que pudiera encontrarse, pegarse rápidamente y sacarse a la venta. Nunca fue un gran negocio. Luego apareció Superman y creó todo un campo nuevo. Él es la clave, el abuelito de todos". 31
\end{abstract}

Will Eisner, recrea con maestría la ebullición editorial de estos años en su novela gráfica The Dreamer (FIG. 5), en la que narra los primeros pasos profesionales de un joven dibujante de cómics y sus sueños por llegar a ganarse la vida dignamente con tan atípica "profesión" en unos años tan duros como los que siguieron a la Gran Depresión americana. El nacimiento del comic-book y su consolidación, el papel de los syndicates, los grandes estudios con dibujantes contratados trabajando en serie. Todo ello está

${ }^{30}$ Gubern, R. Literatura de la imagen, en "Biblioteca Salvat de grandes temas". Barcelona, Salvat Editores, 1973, p. 52.

${ }^{31}$ O'NEIL, D. "Los superhéroes”, en COMA, J. (coord.). Historia de los comics. Vol. 1, Barcelona, Toutain Editor, 1982-1983, p. 250.

CuCo, Cuadernos de cómic número 1. Septiembre de 2013 
recreado en The Dreamer con la viveza y el realismo que solo podría aportar un artista que vivió todo aquello en primera persona, como Will Eisner. ${ }^{32}$

Lo que está claro es que, aunque en un principio el cuaderno de cómics incluía únicamente historias para un público juvenil y adolescente, se había dado el primer paso hacia un modelo que permitiría el desarrollo de historias más largas y con un mayor grado de elaboración — tanto temática como argumentalmente- Hoy en día, el del tebeo es el formato más popular en el mundo de la narración gráfica, gracias sobre todo a las compañías editoriales americanas (en especial Marvel Comics y DC), que publican las historias de sus superhéroes ${ }^{33}$ en él (la baja calidad del papel de estos tebeos permite unos precios muy competitivos y facilita el acceso de un público joven con poco poder adquisitivo).

\footnotetext{
${ }^{32}$ Eisner, junto a Jerry Iger, abrió en 1936 uno de los más importantes talleres de producción de cómics de EE. UU. En ellos el trabajo se desarrollaba en equipo con un objetivo claro: producir el mayor número posible de páginas por semana para aprovisionar la creciente demanda de comic-books exigida por los syndicates periodísticos, que verdaderos "dueños" del mercado del cómic.

${ }^{33}$ En 1938 el número 1 de la revista Action Comics ve la luz en Estados Unidos. En sus páginas, concebido por Joe Shuster y Jerry Siegel, descubrimos a Superman, el primero de los muchos superhéroes que alimentarían el gigantesco fenómeno de masas que es hoy la industria norteamericana del cómic.
} 


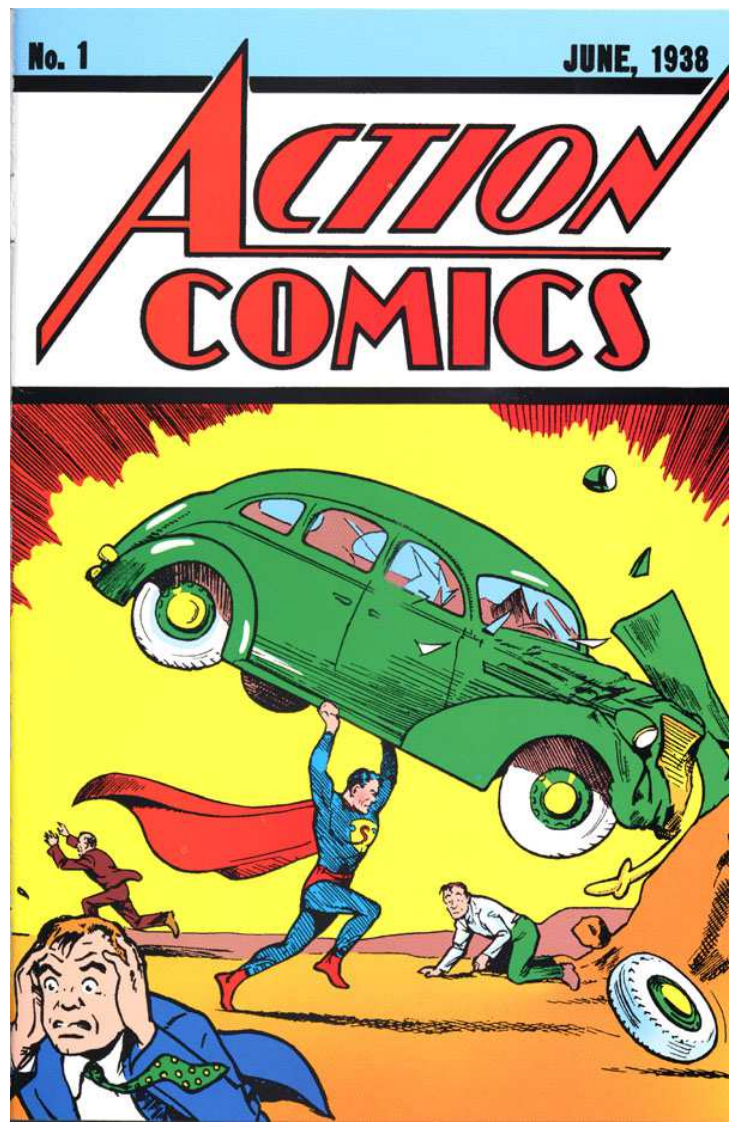

FIG. 4. La primera portada del primero de los superhéroes (1938).
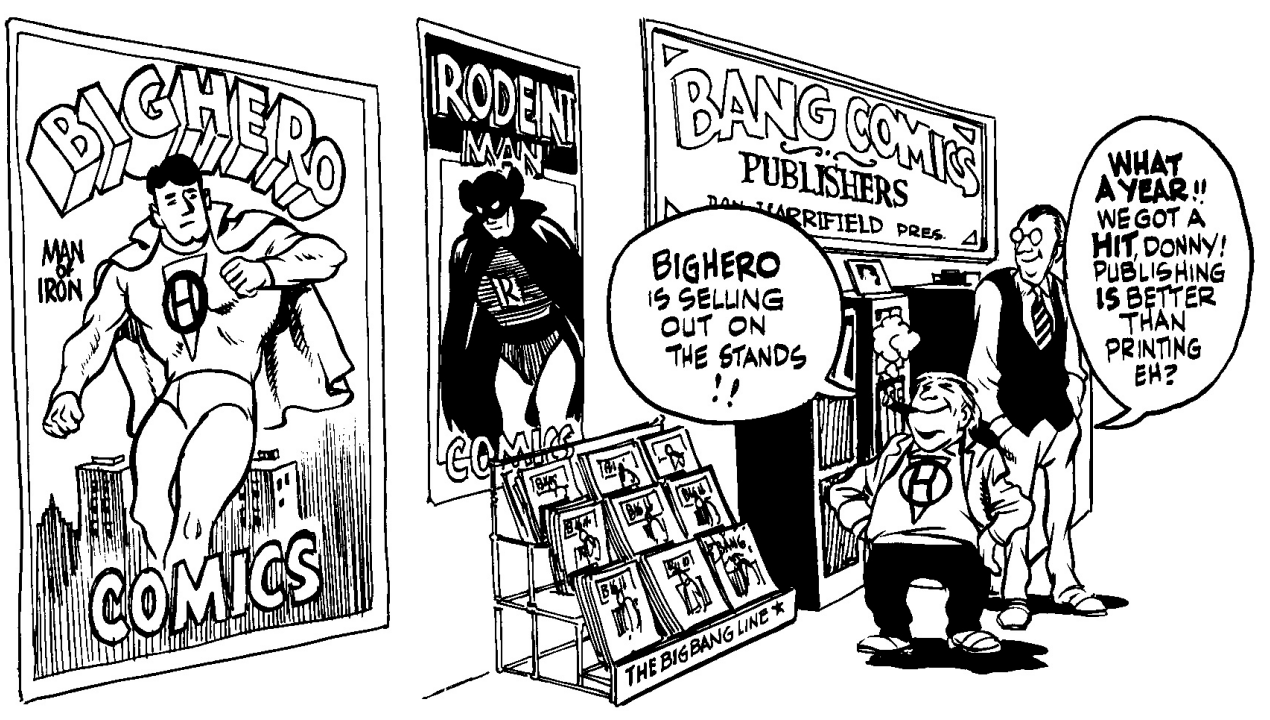

FIG. 5. El mismo Will Eisner, después de estar unos años trabajando para diferentes editores, dirigió su propio taller de creación. De hecho, es uno de los

CuCo, Cuadernos de cómic número 1. Septiembre de 2013 
pocos autores de aquella época que controlaba los derechos de autor de sus propias creaciones y personajes (normalmente en manos de los syndicates que los distribuían). ${ }^{34}$

No podemos continuar sin preguntarnos acerca de los primeros testimonios y la influencia del comic-book en el viejo continente. La indagación ofrece unos resultados sorprendentes. Al referirse a las primeras influencias que ilustradores europeos ejercen sobre los dibujantes de nuestro país, Antonio Martín destaca a Wilhem Busch y Caran D’Ache, cuyas obras aparecían en forma de aleluyas o dispersas en revistas. Destaca, sin embargo, la impresión en 1881 en Barcelona, por C. Verdaguer, de las Historietas Ilustradas; recopilación de obras de W. Busch en “... cuadernos de 16 páginas en formato vertical, que se vendían al precio de medio real, y en cada uno de los cuales se publicaban dos historietas completas del autor alemán". Con la debida cautela que determina este modelo editorial, aún muy incipiente en sus planteamientos y del todo ajeno a la enorme proyección del formato en décadas venideras, estamos de acuerdo con A. Martín cuando prosigue diciendo que:

La importancia de esta publicación radica en su valor como síntoma de una nueva manera de concebir la comercialización de la historieta, ya que estos cuadernos constituyen, con las necesarias salvedades de tiempo y lugar, lo que hoy llamamos tebeos o comic-books. ${ }^{35}$

Resulta sintomático constatar la utilización de algunos elementos editoriales que serían normales en el cómic americano años después, ya en estas primeras publicaciones de cómics europeos, en todo diferentes al soporte periodístico que hemos establecido como receptáculo habitual de los cómics europeos de principios de siglo. Si bien fue en Estados Unidos donde el medio alcanzó un desarrollo más destacable y explotó al máximo todo su potencial, parece que los primeros balbuceos del nuevo discurso deben rastrearse en países como Alemania, Francia o incluso España.

\footnotetext{
${ }^{34}$ EISNER, W. The Dreamer. New York, DC Comics, 1986, p. 31.

${ }^{35}$ Martín, A. Op. cit. p. 14.
}

CuCo, Cuadernos de cómic número 1. Septiembre de 2013 
El caso español es especialmente significativo por la presencia de ciertas constricciones editoriales impuestas por la dictadura:

\begin{abstract}
Bajo el franquismo, hubo una perfecta cohesión entre los intereses industriales e ideológicos. La censura que existe en todos los países cuando se trata de publicaciones infantiles, se impuso con particular virulencia en España y los efectos pudieron ser más o menos directos. Lo más evidente es que editoriales y dibujantes debían contar con la censura y que eso desembocó en el fenómeno bien conocido de la autocensura. Pero la censura repercute también en la calidad de los productos y la elección de los formatos. ${ }^{36}$
\end{abstract}

Efectivamente, la influencia de la censura en la elección y selección de formatos de publicación, no debe ser pasada por alto. Viviane Alary remite al crítico Salvador Vázquez de Parga y su obra Los comics del franquismo, para desentrañar la madeja de decisiones editoriales únicamente comprensibles desde la óptica del simplismo paternalista de las directrices culturales del franquismo: para facilitar el acceso del público al medio cultural, o, mejor dicho, para dirigir a ese público, en los años sesenta y setenta la censura franquista determinó una política de formatos determinados por y para el público lector. Los comic-books apaisados ${ }^{37}$ estaban dirigidos a los niños, mientras que el formato vertical buscaba como destinatario a un público adulto. Los contenidos se veían igualmente condicionados por la naturaleza del público lector: no era admisible que una niña leyera, no ya una publicación adulta, sino un tebeo con temas masculinos.

Frente a la sequía creativa y editorial española, en las mismas fechas se documentan, allende nuestras fronteras, numerosos testimonios de la influencia europea en la evolución del cómic. Así, desde los años setenta proliferaron intentos de elaborar un cómic distinto, más adulto e innovador, utilizando el formato del comic-book como plataforma para la experimentación de nuevos modelos narrativos y el desarrollo de

${ }^{36}$ AlARY, V. "La historieta en España: del presente al pasado", en Cuatro lecciones sobre el cómic. Cuenca, Ediciones de la Universidad de Castilla-La Mancha, 2000, pp. 46-48.

${ }^{37}$ Con un tamaño aproximado de 31 x $21 \mathrm{~cm}$., el formato apaisado español "derivó del modelo italiano de los años treinta, siendo equivalente el término español álbum al italiano albo y al francés album" (GUBERN, R. Op. cit., p. 51).

CuCo, Cuadernos de cómic número 1. Septiembre de 2013

CuCoEstudio 
temas menos convencionales. Europa será, de nuevo, la cuna de tales propuestas. Lo veremos en la siguiente entrega.

\section{Bibliografía}

AlARY, V. "La historieta en España: del presente al pasado", en Cuatro lecciones sobre el cómic. Cuenca, Ediciones de la Universidad de Castilla-La Mancha, 2000, pp. 35-66.

—Historietas, cómics y tebeos españoles. Toulouse, Presses Universitaires deu Mirail, 2003.

AltarribA, A. La España del tebeo. Madrid, Espasa Calpe, 2001.

ARIZMENDI, M. El comic. Barcelona, Editorial Planeta, 1975.

BARBIERI, D. Los lenguajes del cómic. Barcelona, Ediciones Paidós, 1993.

BARRIER, M. 'El nacimiento del 'comic-book'. El largo camino hacia 'Famous Funnies' y Superman", en CoMA, J. (coord.). Historia de los comics. Vol. 1, Barcelona, Toutain Editor, 1982-1983, pp. 197-204.

BARrero, M. "La novela gráfica. Perversión genérica de una etiqueta editorial”, en Literaturas, 2008, disponible on line en http://www.literaturas.com/v010/sec0712/suplemento/articulo8diciembre.html (página web consultada en julio de 2013).

— “El bilbaíno Víctor Patricio de Landaluze, pionero del cómic español en Cuba", en Mundaiz n. ${ }^{\circ}$ 68, San Sebastián, Universidad De Deusto, 2004, pp. 53-79, disponible on line

en

http://www.tebeosfera.com/documentos/textos/el_bilbaino_victor_patricio_de_landaluz e_pionero_del_comic_espanol_en_cuba.html (página web consultada en julio de 2013).

CuCo, Cuadernos de cómic número 1. Septiembre de 2013 
BERMúdeZ, T. Mangavisión (guía del cómic japonés). Barcelona, Ediciones Glénat, 1995.

BERndT, J. El fenómeno manga. Barcelona, Ediciones Martínez Roca, 1996.

Blackbeard, B. The Yellow Kid. A Centenial Celebration of the Kid Who Started the Comics: R. F. Outcault. Northampton (Massachussets), Kitchen Sink Press, 1995.

Bleck, A. “Speech Balloon Evolution”, en Andy’s Early Comics Archive. Disponible on line en http://bugpowder.com/andy/index.html (página web consultada en julio de 2005).

Bozal, V. El siglo de los caricaturistas. Madrid, Historia del Arte, 29, Historia 16, 2000 .

CARrier, D. The Aesthetics of Comics. Pennsylvania, The Pennsylvania State University Press, 2000.

Coma, J. Del gato Félix al gato Fritz. Historia de los comics. Barcelona, Editorial Gustavo Pili, 1979.

—(coord.). Historia de los comics. Barcelona, Toutain Editor, 1982-1983

Conget, J. M. El olor de los tebeos. Valencia, Pre-textos, 2004.

CUADRADO, J. Atlas español de la cultura popular: De la historieta y su uso, 1873-2000 (2 tomos). Madrid, Ediciones Sins Entido / Fundación Germán Sánchez Ruipérez, 2000.

EISNER, W. El comic y el arte secuencial. Barcelona, Norma editorial, 1996.

—La narración gráfica. Barcelona, Norma Editorial, 1998.

—The Dreamer. New York, DC Comics, 1986.

FARR, M. Tintín. El sueño y la realidad. Barcelona, Zendrera Zariquiey, 2002.

CuCo, Cuadernos de cómic número 1. Septiembre de 2013

CuCoEstudio 
Frattini, E. y PALMer, Ó. Guía básica del cómic. Madrid, Nuer Ediciones, 1999.

GARcíA, S. La novela gráfica. Bilbao, Astiberri, 2010.

García Córdoba, C. Los comics. Dibujar con imagen y la palabra. Barcelona, Editorial Humanitas, 1983.

García SÁnchez, S. Sinfonía gráfica. Variaciones en las unidades estructurales y narrativas del cómic. Barcelona, Ediciones Glénat, 2000.

GASCA, L. Los comics en España. Barcelona, Editorial Lumen, 1969.

Gasca, L. y Gubern R. El discurso del comic. Madrid, Ediciones Cátedra, 1994.

Gil GonZÁlez, A. "Literatura e banda deseñada", en CASAS, A. (ed.). Elementos de crítica literaria. Vigo, Ediciones Xerais, 2005.

Gómez SalamancA, D. Tebeo, cómic y novela gráfica: La influencia de la novela gráfica en la industria del cómic en España. Rom RoDRíGUEZ, J. (dir.). Tesis doctoral, Barcelona, Universitat Ramon Llull, 2013.

Gubern, R. El lenguaje de los comics. Barcelona, Ediciones Península, 1981.

_Literatura de la imagen. Barcelona, Salvat Editores, 1973.

— Los medios icónicos de masas. Madrid, Información e Historia (Historia 16), 1997.

GuIRAL, A. (dir. y coord.). Del tebeo al manga: Una historia de los cómics. Barcelona, Panini Comics, 2007-2013.

—Terminología (en broma pero muy en serio) de los comics. Barcelona, Ediciones Funnies, 1998.

Harvey, R. C. The Art of the Comic-book. An Aesthetic History. Jackson, University Press of Mississippi, 1996.

CuCo, Cuadernos de cómic número 1. Septiembre de 2013

CuCoEstudio 
Horn, M. "La continuidad en los comics", en COMA, J. (coord.). Historia de los comics. Vol. 1, Barcelona, Toutain Editor, 1982-1983, pp. 85-92.

— "Realismo y relevancia en los comics. De cómo los comics se volvieron serios durante la Segunda Guerra Mundial y después de ella”, en CoMA, J. (coord.). Historia de los comics. Vol. 1, Barcelona, Toutain Editor, 1982-1983, pp. 273-280.

JiMÉNEZ VAREA, J. Narrativa de la historieta: Análisis narratológico del cómic a través de la obra de Alan Moore. GuARINOs GALÁn, V. (dir.). Tesis doctoral. Sevilla, Universidad de Sevilla, 2002.

Martín, A. Apuntes para una historia de los tebeos. Barcelona, Ediciones Glénat, 2000 .

—Historia del cómic español: 1875-1939. Barcelona, Editorial Gustavo Gili, 1978.

—Los inventores del comic español. 1873/1900. Barcelona, Editorial PlanetaDeAgostini, 2000.

MARSCHALl, R. "Cuando reinaban los relatos. Los años treinta, era de las series con continuidad", en COMA, J. (coord.). Historia de los comics. Vol. 1, Barcelona, Toutain Editor, 1982-1983, p. 113-118.

Merino, A. El cómic hispánico. Colección Signo e Imagen, n. ${ }^{\circ}$ 74. Madrid, Ediciones Cátedra, 2003.

O’NeIL, D. "Los superhéroes", en CoMA, J. (coord.). Historia de los comics. Vol. 1, Barcelona, Toutain Editor, 1982-1983, pp. 247-252.

RosenkranZ, P. Rebel Visions: The Underground Comix Revolution, 1963-1975. Seattle, Fantagraphics Books, 2002. 
SCANCARELly J. "Wallet Family Tree", Gasoline Alley, 1986, disponible on line en uclick.com, http://content.uclick.com/content/tmgas.html (página web consultada en noviembre de 2004).

Spurgeon, T. "Reading Mini-Comics", en The Comics Reporter. Silver City, 10 de octubre de 2004. Disponible on line en http://www.comicsreporter.com/index.php/all_about_comics/all_about/78/ (página web consultada en enero de 2006).

Trabado, J. M. Antes de la novela gráfica. Clásicos del cómic en la prensa norteamericana. Madrid, Ediciones Cátedra, 2012.

VARnum, R. Y GibBons, C. T. (dir.). The Language of Comics. Word and Image. Jackson, University Press of Mississippi, 2001.

VARILLAS, R. La arquitectura de las viñetas. Sevilla, Viaje a Bizancio Ediciones, 2009.

— “Un acercamiento al metacómic. Reflexión, autoparodia y experimentación en las historias gráficas”, en GIL GonZÁleZ, A. (coord.). Anthropos, n. 208. Barcelona, Anthropos Editorial, 2005, pp. 152-166.

—El cómic: texto y discurso. Una propuesta de análisis narratológico. PÉREZ BOWIE, J.A. (dir.). Tesis doctoral. Universidad de Salamanca, Salamanca, 2007.

VV. AA. Comics: clásicos y modernos. Madrid, Promotora de Informaciones (El País), 1988.

Wheeler, D., BeErbohm, R. L. y De SÁ, L. “Töpffer in America”, en Comic Art, n. 3. St. Louis, Comic Art, verano 2003.

WHEELER, D. “Speech Balloon Evolution”, en Andy's Early Comics Archive, disponible on line en http://bugpowder.com/andy/index.html (página web consultada en julio de 2005).

CuCo, Cuadernos de cómic número 1. Septiembre de 2013 